\title{
Modulation of extracellular matrix genes reflects the magnitude of physiological adaptation to aerobic exercise training in humans
} \author{
James A Timmons*1,2, Eva Jansson ${ }^{3}$, Helene Fischer ${ }^{3}$, Thomas Gustafsson ${ }^{3}$, \\ Paul L Greenhaff ${ }^{4}$, John Ridden ${ }^{1,5}$, Jonathan Rachman ${ }^{1,6}$ and \\ Carl Johan Sundberg 1
}

Address: ${ }^{1}$ Department of Physiology and Pharmacology, Karolinska Institutet, Stockholm, SE171 77, Sweden, ${ }^{2}$ Centre for Genomics \& Bioinformatics, Karolinska Institutet, Stockholm, SE171 77, Sweden, ${ }^{3}$ Laboratory Medicine, Division of Clinical Physiology, Karolinska Institutet, Huddinge, 141 86, Sweden, ${ }^{4}$ Centre for Integrated Systems Biology and Medicine, University Medical School, Nottingham, UK, ${ }^{5}$ Department of Enabling Technologies, AstraZeneca, Alderly Park, UK and ${ }^{6}$ OSI Prosidion Ltd, Oxfordshire, OX4 6LT, UK

Email: James A Timmons* - Jamie.Timmons@cgb.ki.se; Eva Jansson - Eva.Jansson@labtech.ki.se; Helene Fischer - Helene.Fischer@labtec.ki.se; Thomas Gustafsson - Thomas.Gustafsson@fyfa.ki.se; Paul L Greenhaff - Paul.Greenhaff@nottingham.ac.uk; John Ridden - John.Ridden@AstraZeneca.com; Jonathan Rachman - jrachman@prosidion.com;

Carl Johan Sundberg - Carl.J.Sundberg@fyfa.ki.se

* Corresponding author

Published: 02 September 2005

BMC Biology 2005, 3:19 doi:10.1186/1741-7007-3-19

This article is available from: http://www.biomedcentral.com/l74/-7007/3/19

(c) 2005 Timmons et al; licensee BioMed Central Ltd.

This is an Open Access article distributed under the terms of the Creative Commons Attribution License (http://creativecommons.org/licenses/by/2.0), which permits unrestricted use, distribution, and reproduction in any medium, provided the original work is properly cited.
Received: 22 March 2005

Accepted: 02 September 2005

\begin{abstract}
Background: Regular exercise reduces cardiovascular and metabolic disease partly through improved aerobic fitness. The determinants of exercise-induced gains in aerobic fitness in humans are not known. We have demonstrated that over 500 genes are activated in response to endurance-exercise training, including modulation of muscle extracellular matrix (ECM) genes. Real-time quantitative PCR, which is essential for the characterization of lower abundance genes, was used to examine 15 ECM genes potentially relevant for endurance-exercise adaptation. Twenty-four sedentary male subjects undertook six weeks of high-intensity aerobic cycle training with muscle biopsies being obtained both before and $24 \mathrm{~h}$ after training. Subjects were ranked based on improvement in aerobic fitness, and two cohorts were formed ( $n=8$ per group): the highresponder group (HRG; peak rate of oxygen consumption increased by $+0.71 \pm 0.1 \mathrm{~L} \mathrm{~min}^{-1}$; $\mathrm{p}<$ $0.000 \mathrm{I}$ ) while the low-responder group (LRG; peak rate of oxygen consumption did not change, $+0.17 \pm 0.1 \mathrm{~L} \mathrm{~min}-1, \mathrm{~ns})$. ECM genes profiled included the angiopoietin $I$ and related genes (angiopoietin 2, tyrosine kinase with immunoglobulin-like and EGF-like domains I (TIEI) and 2 (TIE2), vascular endothelial growth factor (VEGF) and related receptors (VEGF receptor I, VEGF receptor 2 and neuropilin-I), thrombospondin-4, $\alpha 2$-macroglobulin and transforming growth factor $\beta 2$.
\end{abstract}

Results: neuropilin-I (800\%; $p<0.00 I)$ and VEGF receptor $2(300 \% ; p<0.0 I)$ transcript abundance increased only in the HRG, whereas levels of VEGF receptor I mRNA actually declined in the LRG $(p<0.05)$. TIEI and TIE2 mRNA levels were unaltered in the LRG, whereas transcription levels of both genes were increased by 2.5 -fold in the HRG $(p<0.01)$. Levels of thrombospondin-4 $(900 \%$; $p$ $<0.00 \mathrm{I})$ and $\alpha 2$-macroglobulin $(300 \%, \mathrm{p}<0.05)$ mRNA increased substantially in the HRG. In contrast, the amount of transforming growth factor $\beta 2$ transcript increased only in the HRG $(330 \%$; $\mathrm{p}<0.0 \mathrm{I})$, whereas it remained unchanged in the LRG $(-80 \%)$. 


\begin{abstract}
Conclusion: We demonstrate for the first time that aerobic training activates angiopoietin $I$ and TIE2 genes in human muscle, but only when aerobic capacity adapts to exercise-training. The fourfold-greater increase in aerobic fitness and markedly differing gene expression profile in the HRG indicates that these ECM genes may be critical for physiological adaptation to exercise in humans. In addition, we show that, without careful demonstration of physiological adaptation, conclusions derived from gene expression profiling of human skeletal muscle following exercise may be of limited value. We propose that future studies should (a) investigate the mechanisms that underlie the apparent link between physiological adaptation and gene expression and (b) use the genes profiled in this paper as candidates for population genetic studies.
\end{abstract}

\section{Background}

Regular exercise and high aerobic fitness both reduce the risk of cardiovascular- and metabolic-disease-related death for a multitude of potential reasons [1-5]. It is noteworthy that a very large intersubject variation exists when measuring the physiological adaptation to supervised exercise training [6-9]. While some subjects demonstrate a robust increase in aerobic capacity, others seem not to respond substantially at all $[8,10,11]$. This variation also applies to the improvement in insulin sensitivity seen after exercise [9]. Such observations may be important for future cardiovascular health, as an inherent lack of 'trainability' associates with increased cardiovascular risk factors [5]. The mRNA abundance for a huge number of genes $(>500)$ have been shown to be increased many hours after exercise training in humans $[8,12-18]$. However, only very recently have gene expression changes been related to the magnitude of physiological adaptation $[8,9]$. Teran-Garica and others [9] observed a divergent mRNA response in subjects that increase their insulin sensitivity most following endurance training, whereas we have demonstrated that the expression of insulin-like growth factor related genes were increased with training and more markedly in those subjects that most enhanced their aerobic capacity [8]. Little else is known about the relationship between the extent of gene activation and the magnitude of physiological adaptation to exercise training in humans.

Increased aerobic capacity following a period of intense endurance training reflects both central and peripheral adaptations [19-23]. Activation of angiogenesis is presumably an important component of the response to endurance training $[15,20,23-25]$, indicating that substantial remodeling of skeletal muscle extracellular matrix (ECM) is required. Using gene expression profiling, our knowledge of the many factors that regulate the extracellular environment and facilitate vascular remodeling following exercise has improved. Alterations in vascular endothelial growth factor (VEGF) and related receptor(s) transcript expression occur following acute exercise and endurance training $[15,17,26-28]$, indicating that VEGF may be an important exercise factor. More recently, the
Angiopoietin (ANG) signaling pathway has been shown to synergize with VEGF $[29,30]$ and expression of both ANG1 and ANG2 is altered by intense aerobic training in rats [27]. There is currently no information on the physiological regulation of the ANG system in human skeletal muscle following aerobic training. Furthermore, the significance of changes in the abundance of transcripts from genes for various growth factors $[15,26,27]$ has not been examined in the context of changes in aerobic capacity resulting from endurance training.

We therefore set out to establish if greater improvements in systemic cardiovascular adaptation would be associated with changes in muscle gene expression. We did so by examining the expression responses of a number of tissue remodeling genes in subjects that demonstrated either a substantial (high-responder group; HRG) or a modest/ negligible (low-responder group; LRG) response to training [8]. We also aimed to establish if the inclusion of low responders in a gene analysis study could yield misleading information on genes that might genuinely contribute to physiological adaptation to exercise in humans.

\section{Results \\ Physiological parameters}

Table 1 presents the baseline physiological characteristics of the HRG and LRG. As can be observed, no differences in baseline demographics or physiological characteristics existed between LRG and HRG subjects prior to the training program [8]. The combined training response was significantly greater in the HRG $(\mathrm{p}<0.001)$. The reduction in submaximal heart rate was more substantial $(\mathrm{p}<0.01)$ in the HRG $\left(-25.9 \pm 3.6\right.$ beats $\left.\min ^{-1}(\mathrm{BPM})\right)$ vs. the LRG ($10.5 \pm 3.5 \mathrm{BPM}$ ) during a $10 \mathrm{~min}$ fixed-workload, submaximal cycle. The increase in work performed during 15 min cycling after the six weeks of endurance exercise training was $60 \%$ greater $(\mathrm{p}<0.05)$ in the HRG $(+40.8 \pm 4.3$ $\mathrm{kJ})$ than in the LRG $(+24.9 \pm 4.1 \mathrm{~kJ})$. The increase in peak rate of oxygen consumption (peak $\mathrm{VO}_{2}$ ) was four times greater $(\mathrm{p}<0.001)$ in the HRG $\left(+0.71 \pm 0.1 \mathrm{~L} \mathrm{~min}^{-1}\right)$ than in the LRG $\left(+0.17 \pm 0.1 \mathrm{~L} \mathrm{~min}^{-1}\right)$. Importantly, there was no correlation between baseline physiological characteristics and the magnitude of improvement noted; 
Table I: Baseline demographic and physiological parameters

\begin{tabular}{|c|c|c|c|}
\hline & LRGI & HRGI & p-value \\
\hline Height $(\mathrm{cm})$ & $180 \pm 3$ & $183 \pm 3$ & $p=0.53$ \\
\hline Age (year) & $23 \pm 1$ & $24 \pm 1$ & $p=0.54$ \\
\hline Mass (kg) & $77 \pm 3$ & $77 \pm 6$ & $p=0.97$ \\
\hline Mean blood pressure $(\mathrm{mm} \mathrm{Hg})$ & $92 \pm 1$ & $88 \pm 4$ & $p=0.25$ \\
\hline Peak $\mathrm{VO}_{2}\left(\mathrm{~L} \mathrm{~min}^{-1}\right)^{2}$ & $3.7 \pm 0.1$ & $3.5 \pm 0.3$ & $p=0.48$ \\
\hline Resting heart rate (BMP) & $71 \pm 5$ & $70 \pm 6$ & $p=0.94$ \\
\hline Submaximal heart rate ${ }^{3}$ & $170 \pm 5$ & $17 \mid \pm 5$ & $p=0.85$ \\
\hline Respiratory exchange ratio 4 & $1.0 \pm 0.0$ & $1.0 \pm 0.0$ & $p=0.45$ \\
\hline 15 min work $(\mathrm{kJ})^{5}$ & $220 \pm 9$ & $204 \pm 16$ & $p=0.37$ \\
\hline
\end{tabular}

IValues are mean $( \pm$ SEM) taken prior to training.

$2 \mathrm{Peak} \mathrm{VO}_{2}$ is the increase in 'maximal' oxygen uptake measured during an incremental maximal exercise protocol.

${ }^{3}$ Submaximal heart rate was measured during 10 min constant load cycling at $75 \%$ peak $\mathrm{VO}_{2}$.

${ }^{4}$ The respiratory exchange ratio was obtained during $10 \mathrm{~min}$ of submaximal exercise at $75 \%$ of pretraining peak $\mathrm{VO}_{2}$.

$5 / 5$ min work is the total work done in 15 min of self-paced cycling.

this observation is consistent with those from previous studies [31].

\section{Growth factor-related genes}

Subjects in both groups underwent six weeks of endurance training. Gene expression levels were then measured $24 \mathrm{~h}$ after the last training session. Levels of VEGF gene expression were not significantly altered in either group (Fig. 1). Likewise, levels of VEGF receptor 1 (VEGFR1) mRNA did not significantly increase in the HRG and actually declined in the LRG $(\mathrm{p}<0.05)$. However, VEGF receptor 2 (VEGFR2) mRNA expression increased by threefold in the HRG $(\mathrm{p}<0.01)$, whereas it did not significantly change in the LRG. Similarly, mRNA for the VEGFR2 coreceptor Neuropilin-1 (NP-1) increased in the HRG (p < 0.001 ) but not in the LRG (Fig. 1). Expression of the hypoxia-inducible factor $1 \alpha(H I F)$ gene did not significantly change after endurance training. Regulation by endurance training of ANG-related genes was only observed in the HRG (Fig. 2). Levels of mRNA coding for ANG1, an agonist for the Tyrosine kinase with immunoglobulin-like and EGF-like domains 2 (TIE2) receptor, increased significantly in the HRG $(\mathrm{p}<0.05)$, although ANG2 levels did not change significantly in either group. Likewise, transcription of tyrosine kinase with immunoglobulin-like and EGF-like domains 1 (TIE1; $3.4 \pm 1.0$-fold increase; $\mathrm{p}<0.01$ ) and TIE2 increased in the HRG only ( $<<0.01$; Fig. 3 ).

\section{Extracellular matrix growth factor binding genes}

Using our microarray dataset [8], we selected ECM factors that (a) demonstrated evidence of being modulated by exercise training and (b) were relevant for ECM remodeling [32-34]. These genes included ones that encoded structural components of blood vessels (collagen type $I I I \alpha 1$ ) or known regulators of tissue angiogenesis (collagen type $X V \alpha 1$ ), factors known to influence ECM-derived growth factor activity ( $\alpha 2$-macroglobulin (A2M) and thrombospondin-4 (THBS4)), transforming growth factor $\beta 2$ (TGFB2; a potent regulator of tissue remodeling) and TGFB receptor II (TGFBR2). The level of fetal vascular collagen (i.e., collagen type III $\alpha 1$ ) gene expression was increased $14.7 \pm 2.8$-fold $(\mathrm{p}<0.001)$ in the HRG and 8.5 \pm 4.1 fold in the LRG $(\mathrm{p}<0.001)$. The level of collagen type $X V \alpha 1$ expression increased in both groups: the HRG demonstrated a $7.6 \pm 3.6$-fold increase $(\mathrm{p}<0.001)$ while the LRG demonstrated a $2.7 \pm 0.5$-fold increase $(\mathrm{p}<0.01)$ in expression of the gene (Fig. 3 ). In contrast, while both A2M and THBS4 were significantly upregulated in the HRG (threefold $(\mathrm{p}<0.01)$ and tenfold $(\mathrm{p}<0.001)$ increases, respectively), in the LRG the THBS4 response was more modest $(2.5$-fold; $\mathrm{p}<0.01)$ and $A 2 \mathrm{M}$ mRNA levels did not significantly change. TGFB2 was significantly upregulated in the HRG ( $\mathrm{p}<0.01)$, whereas, if anything, it tended to be downregulated in the LRG (Fig. 3). The level of TGFBR2 expression was unchanged in the LRG, but threefold increased in the HRG ( $p<0.001$; Fig. $3)$. Finally, three genes unrelated to ECM biology but previously described as being modulated by exercise [8], interleukin 17D, Rho-GTPase-activating-protein 1 and myristoylated alanine-rich protein kinase $C$ substrate, did not significantly vary in their expression between HRG and LRG (data not shown).

\section{Discussion}

Classic alterations in skeletal muscle phenotype following physical training include improved fatigue resistance, enhanced aerobic capacity and greater insulin sensitivity $[9,23,25,35,36]$. The significance of an individual's ability to adapt to exercise training may ultimately influence multiple risk factors important for long term cardiovascular health [5]. In the present study we demonstrate for the first time that ANG genes are substantially modulated in 


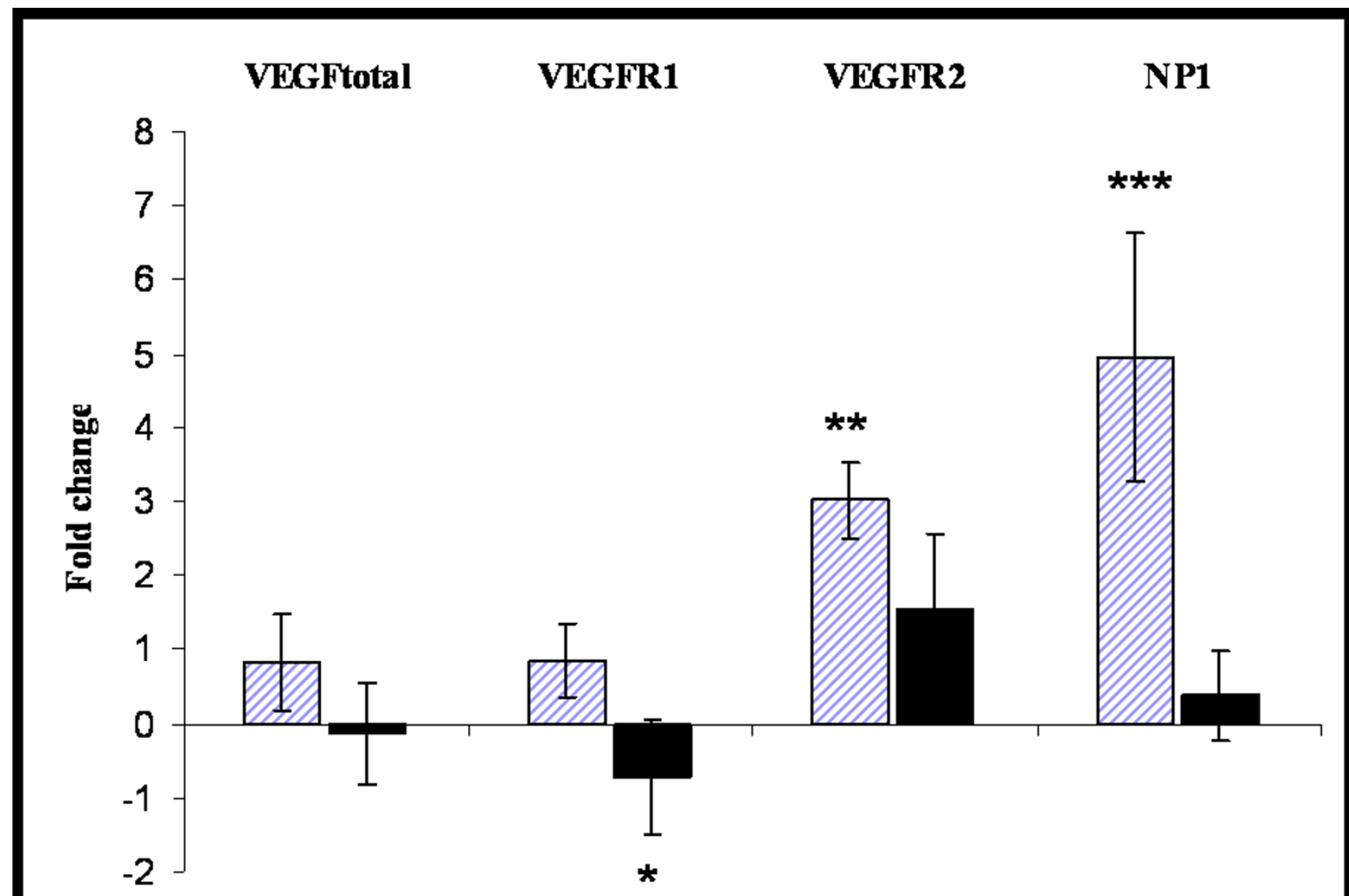

High responder group

Low re sponder group

\section{Figure I}

Change in Vascular endothelial growth factor-related gene expression following endurance training. Values are fold changes in human skeletal muscle gene expression (mean $\pm \mathrm{SE}$ ) following six weeks of aerobic training. Gene expression was determined using real-time quantitative PCR. Following six weeks training $(n=24)$, the eight highest and eight lowest responders to exercise training were identified using the sum of (a) the percent improvement in maximal aerobic capacity, (b) the percent reduction in submaximal heart rate during 15 min fixed-workload, submaximal cycling and (c) the percent improvement in work done during a 15 min maximal cycling test. This ranking was carried out before any genomic analysis was carried out. The training responses were evaluated by two-way ANOVA and Bonferoni post-hoc tests. $*$ indicates $p<0.05$, $* *$ indicates $\mathrm{p}<0.0 \mathrm{I}$ and $* * *$ indicates $\mathrm{p}<0.00 \mathrm{I}$.

humans following a six-week aerobic training program. Overall, many ECM-gene transcripts were only modulated in subjects that demonstrated a concurrent improvement in aerobic capacity. Our data suggest that activation of ECM genes may help determine the cardiovascular adaptation to aerobic exercise in humans. The present findings also indicate that, when carrying out expression studies of gene transcripts in humans, prior to any interpretation of muscle gene expression responses, attention must be afforded to the presence of physiological adaptation.

\section{Modulation of genes that regulate extracellular matrix remodeling}

We still have an incomplete understanding of the endogenous processes that regulate physiological adaptation to aerobic exercise. Vascular growth factors not only regulate tissue blood vessel density, but also enhances the expression of proteins that regulate oxygen levels in tissue [37]. Hence, it is naïve to think about the role of such growth factors only in terms of regulating tissue capillary density. Altered expression of HIF responsive genes (e.g. VEGF or 


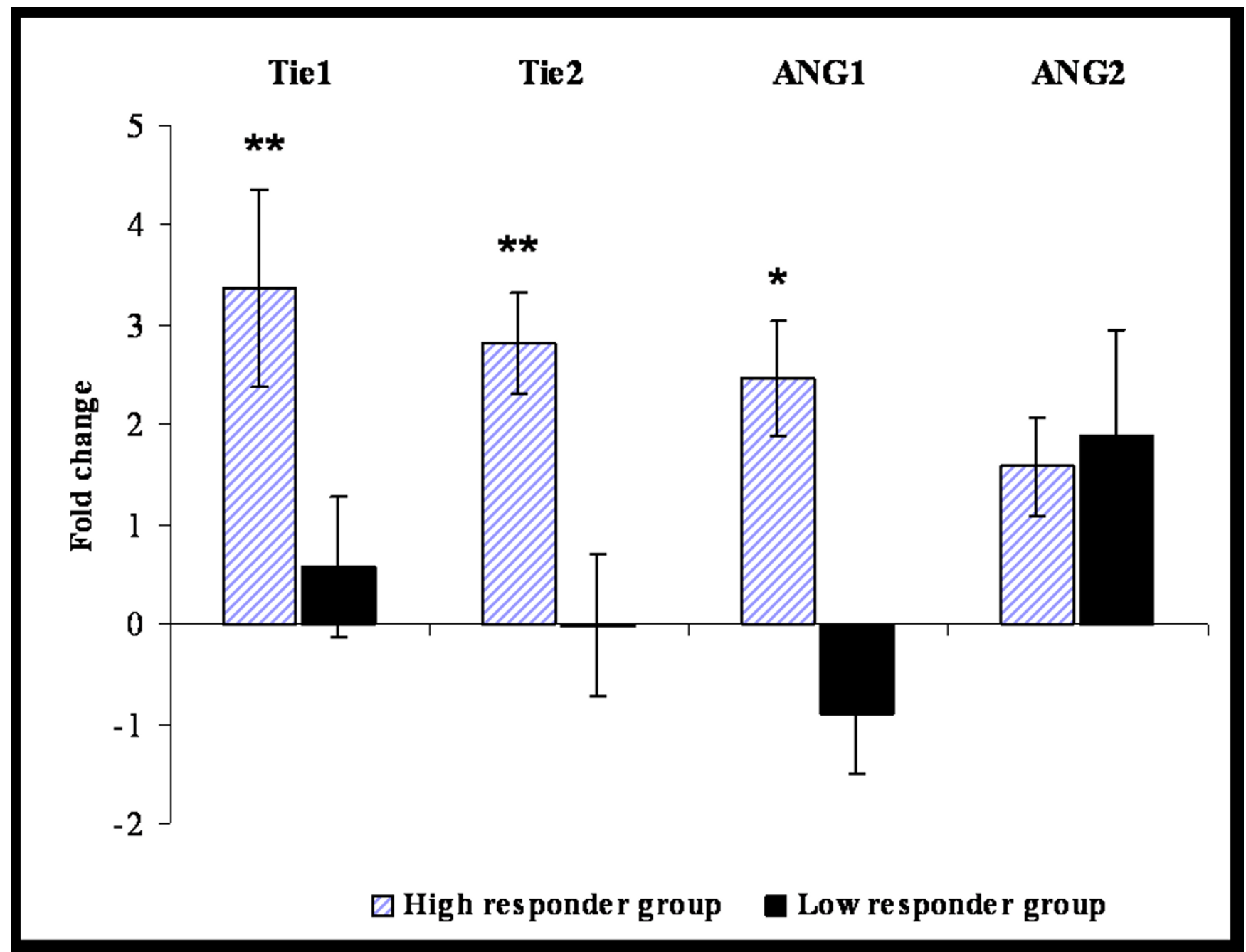

\section{Figure 2}

Changes in Angiopoietin-related gene expression following endurance training. Values are -fold changes in human skeletal muscle gene expression (mean $\pm \mathrm{SE}$ ) following six weeks of aerobic training, as described in Fig. I. * indicates $\mathrm{P}<0.05$, ** indicates $\mathrm{p}<0.0 \mathrm{I}$ and $* * *$ indicates $\mathrm{p}<0.00 \mathrm{I}$.

VEGFR1) typically reflects the posttranslational stabilization of HIF1 $\alpha$ protein [38], and consistent with this dogma, HIF mRNA was not significantly upregulated. VEGFR2, considered the major mediator of VEGF-Arelated angiogenesis, was significantly upregulated in the HRG only. Furthermore, NP-1, a facilitator of VEGF ${ }_{165}$ action at VEGFR2, was markedly elevated in the HRG and unchanged in the LRG (Fig. 1). Upregulation of the VEGFR2 coreceptor transcript provides some evidence for greater VEGF activity in the HRG, as enhanced NP-1 gene expression can be mediated by VEGF signaling $[39,40]$. The significance of the downregulation of VEGFR1 in the LRG is unclear, but plausibly reflects an (unsuccessful) compensation for the general lack of VEGFR2/NP-1 gene activation in the LRG, as studies indicate VEGFR1 may oppose VEGF signaling via VEGFR2 in some situations [41].

The present study represents the first characterization of expression levels of the human ANG gene family in response to endurance-exercise training. Recently, the Terjung laboratory examined the impact of exercise on the angiopoietin system in rodents [27]. Alterations in TIE2, ANG1 and ANG2 transcript expression were profiled $2 \mathrm{~h}$ post exercise in various muscle groups taken from Sprague-Dawley rats after 1 to 24 days of intense aerobic running [27]. In rodents, activation of TIE2 and ANG2 was, broadly speaking, rather similar across each muscle 


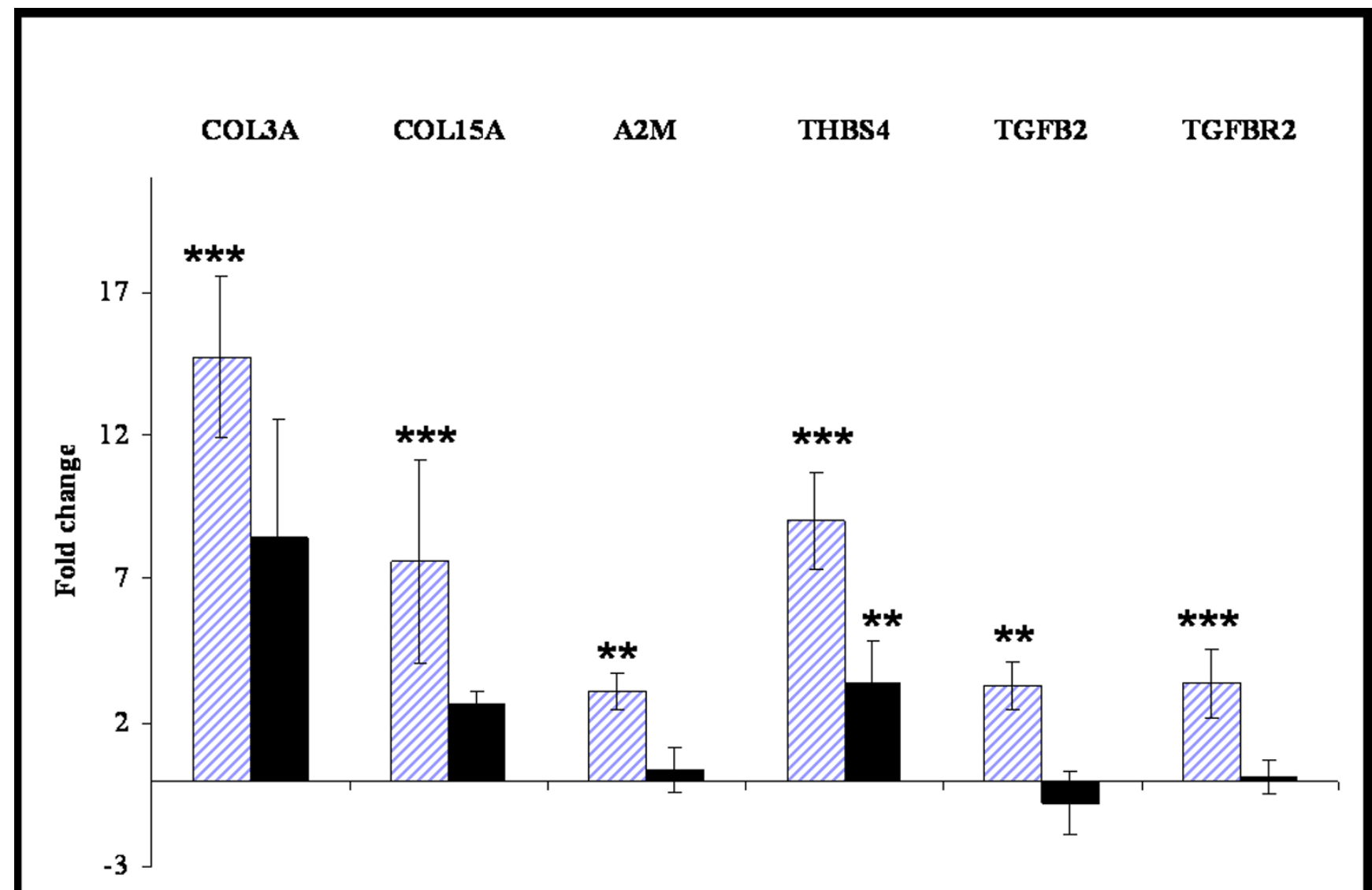

$\square$ High responder group $\square$ Low responder group

Figure 3

Change in extracellular-matrix-related gene expression following endurance training. Values are -fold changes in human skeletal muscle gene expression (mean $\pm \mathrm{SE}$ ) following six weeks of aerobic training, as described in Fig. I. * indicates $\mathrm{P}$ $<0.05$, ** indicates $\mathrm{p}<0.0 \mathrm{I}$ and $* * *$ indicates $\mathrm{p}<0.00 \mathrm{I}$.

tissue, especially when one considers that recruitment patterns would differ between the various muscle groups studied. The ANG1 response, however, differed both across muscle groups and when compared with our human data. In contrast with the upregulation of ANG1 seen in humans in the HRG (Fig. 2), in the rat ANG1 expression was slightly downregulated in oxidative muscle groups, while 'fast' gastrocnemius demonstrated only a modest increase in ANG1 expression [27]. It has recently been established that either pre- [30] or concurrent administration [29] of ANG1 synergizes with VEGF to promote hindlimb angiogenesis. Thus it makes sense that effective aerobic training might result in stable increases in ANG1 expression (as we have found). Therefore, differences between our human data and the rodent study by Lloyd et al [27] perhaps reflect differing muscle sampling times. Future human studies should ideally use multiple time points post exercise to clarify these issues. However, care should be taken to verify that the subjects studied are able to demonstrate a measurable aerobic training response otherwise such results may be unreliable.

It has been hypothesized that changes in the ratio between levels of ANG1 and ANG2 is of physiological importance $[27,42]$ by contributing to the stabilization of the primary endothelial structures [43]. While ANG1's ability to antagonize ANG2 at the TIE2 receptor may be cell-type specific $[42,44,45]$ and has yet to be proven to be important in vivo, it is interesting to note that ANG1 and ANG2 appear to have identical binding affinities for the TIE2 receptor, whereas a threefold molar excess of ANG2 is required to antagonize ANG1 activity [45]. If the gene 
expression patterns observed in the present study translate to greater Tie2 receptor signaling, then our data supports the idea that ANG1 cooperates with other growth factors in vivo to regulate and promote functional angiogenesis. This hypothesis clearly requires further investigation. ANG1 and TGFB signaling facilitate the maturation of VEGF-stimulated collateral vessel growth in adult tissue $[29,30,46]$. Notably, TGFB2 and TGFBR2 were substantially upregulated only in the HRG. This observation again suggests that the ECM-related gene response in the HRG may have allowed for greater tissue remodeling, which would have contributed to the fourfold greater increase in aerobic capacity.

To further examine the idea that the pattern of transcript expression in the HRG contributed to the enhanced aerobic adaptation, we profiled a second set of genes chosen from a gene-array study [8]. For example, upregulation of potent growth factors should be accompanied by upregulation of endogenous regulators, so that physiological control could be maintained. A2M is an ECM protein known to bind and regulate growth factor activity $[47,48]$. A2M was substantially upregulated in the HRG only (Fig. 3 ) suggesting that there was more active growth factor signaling within the ECM of the HRG. Thrombospondins also regulate ECM growth factors, including TGFB activity. In addition, a loss of function polymorphism in THBS4 is strongly associated with premature coronary artery disease [49]. In the present study a more substantial increase in THBS4 mRNA expression was noted in the HRG (Fig. 3). As dysfunction of THBS4 and lack of cardiorespiratory fitness are both risk factors for cardiovascular disease, it is plausible that THBS4 plays a role in the cardioprotective effects of exercise. Further analysis is required to establish if such a relationship exists within a larger human population.

\section{Conclusion}

There was unquestionably a differential physiological response between the groups, as the HRG increased their aerobic capacity by, on average, $0.71 \mathrm{~L} \mathrm{~min}^{-1}$, whereas the LRG did not significantly increase their aerobic capacity $\left(+0.17 \mathrm{~L} \mathrm{~min}^{-1}\right)$. At this time, our data cannot directly attribute cause-and-effect for the differentially responding genes. Although we profiled changes in skeletal muscle ECM-related gene expression changes, we are not implying that only the local (i.e., in skeletal muscle) role of these genes contributes to the magnitude of the training adaptation. It is entirely plausible that the observed difference between our cohorts reflects a genotype-dependant response, which would impact on gene expression in a range of tissues important for cardiovascular adaptation to endurance-exercise training. Importantly, histological analysis of muscle would not address this possibility. Instead, we would suggest that these differentially expressed genes represent reasonable candidates for future polymorphism studies in larger populations. Our data also demonstrates that direct evidence for physiological adaptability must be presented prior to concluding that gene transcript alterations may or may not occur during the physiological adaptation to exercise.

\section{Methods \\ Human and physiological measurements}

The study was approved by the ethics committee of the Karolinska Institutet, Stockholm, Sweden, and informed consent was obtained from each of the volunteers. Subjects abstained from strenuous exercise during the three weeks prior to obtaining pretraining muscle biopsies (taken from the vastus lateralis). Twenty-four subjects trained under full supervision on a cycle ergometer four times a week ( $45 \mathrm{~min}$ ) at $75 \%$ of their pretraining peak $\mathrm{VO}_{2}$ for six weeks. Posttraining biopsies were taken $24 \mathrm{~h}$ after the last training session. Physiological measurements and muscle biopsies were performed as previously described $[8,16,50]$. All physiological parameters were derived from a minimum of two assessments, taken on separate days. Peak $\mathrm{VO}_{2}$ was determined using a cycle ergometer (Rodby, Sweden). An incremental protocol was combined with continuous analysis of respiratory gases using the Sensormedic ventilator (Sensormedic Co., USA). At peak $\mathrm{VO}_{2}$ the respiratory exchange ratio and heart rate exceeded 1.1 and 190 BPM, respectively, on all occasions. Total amount of work done in $15 \mathrm{~min}$ of cycling was determined using a self-paced protocol (Lode, Netherlands, test-re-test variability $<5 \%$ ). Submaximal physiological parameters were determined during two separate 10 min constant-load, submaximal cycling sessions (carried out at $75 \%$ of pretraining peak $\mathrm{VO}_{2}$ ).

Two groups were selected from a larger training cohort based on the magnitude of their training response (Table $1)$. The two groups represented the eight subjects that demonstrated the largest improvement in physiological capacity (HRG) and the eight subjects that demonstrated minimal changes in physiological capacity (LRG) after following an identical supervised training program. The average training-induced change in peak $\mathrm{VO}_{2}$ in the LRG equates to the lower $\sim 10 \%$ of responses observed in the HERITAGE study [6], whereas the response in the HRG represents the top $\sim 10 \%$ of responses. This information helps to establish a 'population perspective' on the responses observed in the present study. Subjects were assigned to each group after being ranked on the basis of the sum of changes in three main physiological parameters: (a) percent improvement in peak aerobic capacity, (b) percent reduction in submaximal heart rate during 10 min fixed-workload, submaximal cycling and (c) percent improvement in work done during a 15 min maximal cycling test. A combination of physiological markers of 
adaptation was used to ensure that no spurious individual physiological measurement would compromise the overall categorization of a subject [8]. Peak aerobic capacity, decreased exercise-induced-increases in heart rate and aerobic performance are all valid and accepted responses to aerobic exercise training. No molecular or biochemical analysis was carried out until the subjects were assigned to their particular group. This type of novel analysis strategy has previously been used by our group and also, more recently, by Bouchard et al $[8,9]$

\section{Real-time quantitative PCR and statistics}

Total RNA was prepared using the TRIzol method (Invitrogen, USA) and quantified using a spectrophotometer. Two $\mu \mathrm{g}$ of RNA was reverse transcribed by Superscript reverse transcriptase (Life Technologies, Sweden) using random hexamer primers (Roche Diagnostics $\mathrm{GmbH}$, Mannheim, Germany) in a total volume of $20 \mu \mathrm{l}$. Detection of mRNA was performed using a ABI-PRISM ${ }^{\circledast} 7700$ Sequence Detector (Perkin-Elmer Applied Biosystems Inc, Foster City, CA, USA). All reactions were performed in 96well MicroAmp Optical plates (Perkin-Elmer Applied Biosystems Inc.). Amplification aliquots contained $5 \mu \mathrm{l}$ of the sample cDNA, the TaqMan Universal PCR master mix (Perkin-Elmer Applied Biosystems Inc.) and an optimized concentration of each primer and probe, prepared according to the manufacturer's recommendation, in a final volume of $25 \mu \mathrm{l}$. 18S rRNA was selected as an endogenous control to correct for potential variations in RNA loading into the cDNA synthesis reaction. The $18 \mathrm{~S}$ rRNA control was run in triplicate in separate wells (using 1:2000 dilution of the original cDNA). Thermal cycling conditions were, initially, $2 \mathrm{~min}$ at $50^{\circ} \mathrm{C}$ followed by $10 \mathrm{~min}$ at $95^{\circ} \mathrm{C}$, and then, subsequently, 45 cycles of $15 \mathrm{~s}$ at $95^{\circ} \mathrm{C}$ and 1 $\min$ at $65^{\circ} \mathrm{C}$.

Oligonucleotide primers and TaqMan probes were designed using Primer Express version 1.5 (Perkin-Elmer Applied Biosystems Inc.) and synthesized by Cybergene (Stockholm, Sweden) or ordered as a 'gene assay by demand' product (Perkin-Elmer Applied Biosystems Inc). The sequences or 'gene assay by demand' numbers can be provided on request. The probes were designed to cover exon-exon boundaries to avoid amplification of genomic DNA. As there are no predetermined low-abundance "house-keeping" genes for this experimental paradigm, the $\Delta \Delta \mathrm{Ct}$ method [51] was used to calculate relative changes in mRNA abundance. The threshold cycle (Ct) for $18 \mathrm{~S}$ was subtracted from the $\mathrm{Ct}$ for the target gene to adjust for variations in mRNA/cDNA generation efficacy. This was carried out for both pre- and posttraining samples. The preexercise value reflects baseline gene expression levels and was subtracted from the postexercise value to calculate the increase or decrease in mRNA abundance.
A two-way mixed model ANOVA (GraphPad Prism 4.0) was used to establish whether a significant interaction between 'group' and 'extracellular gene responses' occurred ( $p<0.0001)$ and to confirm appropriate baseline subject matching $(\mathrm{p}<0.0001)$. Bonferoni post-hoc testing established which individual gene responses were significant for each subgroup, and this analysis was used for the basis of the discussion. For comparison between HRG and LRG training response data (e.g., peak $\mathrm{VO}_{2}$ ), a two-tailed unpaired t-test was utilized. Significance was accepted at the $5 \%$ level. Data are mean \pm SE.

\section{List of abbreviations used}

a2-Macroglobulin (AM2)

Angiopoietin (ANG)

Angiopoietin 1 (ANG 1)

Angiopoietin 2 (ANG2)

Beats per minute (BPM)

Collagen type III $\alpha 1$ (COL3A1)

Collagen type XV $\alpha 1$ (COL15A1)

Extracellular matrix (ECM)

High-responder group (HRG)

Hypoxia-inducible factor $1 \alpha$ (HIF)

Interleukin 17D (IL17D)

Low responder group (LRG)

Myristoylated alanine-rich protein kinase $\mathrm{C}$ substrate (MARKS)

Neuropilin (NP-1)

Rate of oxygen consumption $\left(\mathrm{VO}_{2}\right)$

Rho-GTPase-activating protein 1 (ARHGAP1)

Threshold cycle (Ct)

Thrombospondin-4 (THBS4)

Transforming growth factor $\beta$ (TGFB)

Transforming growth factor $\beta 2$ (TGFB2)

Transforming growth factor $\beta$ receptor II (TGFBR2) 
Tyrosine kinase with immunoglobulin-like and EGF-like domains 1 (TIE1)

Tyrosine kinase with immunoglobulin-like and EGF-like domains 2 (TIE2)

\section{Vascular endothelial growth factor (VEGF)}

Vascular endothelial growth factor related receptor 1 (VEGFR1)

Vascular endothelial growth factor related receptor 2 (VEGFR2)

\section{Authors' contributions}

EJ, JAT, PLG, JRa, JRi and CJS were responsible for the design and management of the endurance training study, subject recruitment and tissue sampling. JAT was responsible for generating the strategy for the gene expression analysis. JAT selected the biological theme and the majority of the genes to be profiled in this particular study, while TG selected some of the angiopoietin genes and ordered the majority of the primers. TG and HF were responsible for organizing the real time PCR analysis while JAT was responsible for the subsequent calculations and computations. JAT and CJS were responsible for drafting and revising the manuscript, respectively.

\section{Acknowledgements}

The authors would like to thank Laura Svensson for providing technical assistance and Helene Ameln for designing the HIFI $\alpha$ primers. This work was supported by the Swedish Heart-Lung Association, the Swedish Sports Council, the Thurings Foundation and the Swedish Medical Research Council (VR). JAT is supported by the Swedish Diabetes Association.

\section{References}

I. Kraus WE, Houmard JA, Duscha BD, Knetzger KJ, Wharton MB, McCartney JS, Bales CW, Henes S, Samsa GP, Otvos JD, et al.: Effects of the amount and intensity of exercise on plasma lipoproteins. N EnglJ Med 2002, 347: |483-| 492.

2. Frederiksen $\mathrm{H}$, Christensen $\mathrm{K}$ : The influence of genetic factors on physical functioning and exercise in second half of life. Scand J Med Sci Sports 2003, I3:9-18.

3. Manson JE, Greenland P, LaCroix AZ, Stefanick ML, Mouton CP, Oberman A, Perri MG, Sheps DS, Pettinger MB, Siscovick DS: Walking compared with vigorous exercise for the prevention of cardiovascular events in women. N Engl J Med 2002, 347:716-725.

4. Wei M, Gibbons LW, Mitchell TL, Kampert JB, Lee CD, Blair SN: The association between cardiorespiratory fitness and impaired fasting glucose and type 2 diabetes mellitus in men. Ann Intern Med 1999, 130:89-96.

5. Wisloff U, Najjar SM, Ellingsen O, Haram PM, Swoap S, Al-Share Q, Fernstrom M, Rezaei K, Lee SJ, Koch LG, Britton SL: Cardiovascular risk factors emerge after artificial selection for low aerobic capacity. Science 2005, 307:418-420.

6. Bouchard C, Rankinen T: Individual differences in response to regular physical activity. Med Sci Sports Exerc 200I, 33:S446-45I. discussion S452-443

7. Rico-Sanz J, Rankinen T, Rice T, Leon AS, Skinner JS, Wilmore JH, Rao DC, Bouchard C: Quantitative trait loci for maximal exercise capacity phenotypes and their responses to training in the HERITAGE Family Study. Physiol Genomics 2004, I 6:256-260.
8. Timmons JA, Larsson O, Jansson E, Fischer H, Gustafsson T, Greenhaff PL, Ridden J, Rachman J, Peyrard-Janvid M, Wahlestedt C, Sundberg C): Human muscle gene expression responses to endurance training provide a novel perspective on Duchenne muscular dystrophy. Faseb J 2005, 19:750-760.

9. Teran-Garcia M, Rankinen T, Koza RA, Rao DC, Bouchard C: Endurance training-induced changes in insulin sensitivity and gene expression. Am J Physiol Endocrinol Metab 2005, 288:E I I 68-E I I 78.

10. Lortie G, Simoneau JA, Hamel P, Boulay MR, Landry F, Bouchard C: Responses of maximal aerobic power and capacity to aerobic training. Int J Sports Med 1984, 5:232-236.

II. Prud'homme D, Bouchard C, Leblanc C, Landry F, Fontaine E: Sensitivity of maximal aerobic power to training is genotypedependent. Med Sci Sports Exerc 1984, 16:489-493.

12. Pilegaard H, Saltin B, Neufer PD: Exercise induces transient transcriptional activation of the PGC-I alpha gene in human skeletal muscle. J Physiol 2003, 546:85I-858.

13. Bengtsson J, Gustafsson T, Widegren U, Jansson E, Sundberg C): Mitochondrial transcription factor $A$ and respiratory complex IV increase in response to exercise training in humans. Pflugers Arch 200I, 443:6I-66.

14. Hittel DS, Kraus WE, Tanner CJ, Houmard JA, Hoffman EP: Exercise training increases electron and substrate shuttling proteins in muscle of overweight men and women with the metabolic syndrome. J Appl Physiol 2005, 98:168-179.

15. Jensen L, Pilegaard H, Neufer PD, Hellsten Y: Effect of acute exercise and exercise training on VEGF splice variants in human skeletal muscle. Am J Physiol Regul Integr Comp Physiol 2004, 287:R397-402.

16. Norrbom J, Sundberg CJ, Ameln H, Kraus WE, Jansson E, Gustafsson T: PGC-I alpha mRNA expression is influenced by metabolic perturbation in exercising human skeletal muscle. J Appl Physiol 2004, 96:189-194.

17. Richardson RS, Wagner H, Mudaliar SR, Saucedo E, Henry R, Wagner PD: Exercise adaptation attenuates VEGF gene expression in human skeletal muscle. Am J Physiol Heart Circ Physiol 2000, 279:H772-778.

18. Pedersen BK, Steensberg A, Fischer C, Keller C, Keller P, Plomgaard $P$, Febbraio $M$, Saltin $B$ : Searching for the exercise factor: is IL6 a candidate? J Muscle Res Cell Motil 2003, 24: I I3-I I9.

19. Jensen L, Bangsbo J, Hellsten Y: Effect of high intensity training on capillarization and presence of angiogenic factors in human skeletal muscle. J Physioln 2004, 557:57I-582.

20. Hepple RT, Mackinnon SL, Goodman JM, Thomas SG, Plyley MJ: Resistance and aerobic training in older men: effects on VO2peak and the capillary supply to skeletal muscle. J Appl Physiol 1997, 82:1305-1310.

21. Klausen K, Andersen LB, Pelle I: Adaptive-changes in work capacity, skeletal-muscle capillarization and enzyme levels during training and detraining. Acta Physiologica Scandinavica 1981, I | 3:9-16.

22. Ingjer F: Effects of endurance training on muscle-fiber ATPase activity, capillary supply and mitochondrial content in man. J Physiol 1979, 294:419-432.

23. Saltin B, Gollnick P: Skeletal muscle adaptability: significance for metabolism and performance. In Handbook of Physiology Skeletal muscle Volume 10. Edited by: Peachey L, Adrian RH, Geiger SR. Bethesda, Maryland: American Physiological Society; 1983.

24. Sundberg $\mathrm{C}$ ): Exercise and training during graded leg ischaemia in healthy man with special reference to effects on skeletal muscle. Acta Physiol Scand Suppl 1994, 6 I 5: 1-50.

25. Blomqvist CG, Saltin B: Cardiovascular adaptations to physicaltraining. Annual Review of Physiology 1983, 45: I69-189.

26. Gustafsson T, Puntschart A, Kaijser L, Jansson E, Sundberg Cl: Exercise-induced expression of angiogenesis-related transcription and growth factors in human skeletal muscle. Am J Physio 1999, 276:H679-685.

27. Lloyd PG, Prior BM, Yang HT, Terjung RL: Angiogenic growth factor expression in rat skeletal muscle in response to exercise training. Am J Physiol Heart Circ Physiol 2003, 284:HI668-I678.

28. Gustafsson T, Ameln H, Fischer H, Sundberg CJ, Timmons JA, Jansson $E$ : VEGF-A splice variants and related receptor expression in human skeletal muscle following submaximal exercise. J Appl Physiol 2005, 98:2137-2।46.

29. Shyu KG, Chang H, Isner JM: Synergistic effect of angiopoietin- I and vascular endothelial growth factor on neoangiogenesis 
in hypercholesterolemic rabbit model with acute hindlimb ischemia. Life Sci 2003, 73:563-579.

30. Yamauchi A, Ito Y, Morikawa M, Kobune M, Huang J, Sasaki K, Takahashi K, Nakamura K, Dehari H, Niitsu Y, et al.: Pre-administration of angiopoietin-I followed by VEGF induces functional and mature vascular formation in a rabbit ischemic model. J Gene Med 2003, 5:994-1004.

31. Kohrt WM, Malley MT, Coggan AR, Spina RJ, Ogawa T, Ehsani AA, Bourey RE, Martin WH 3rd, Holloszy JO: Effects of gender, age, and fitness level on response of VO2max to training in 60-7I yr olds. J Appl Physiol I99I, 7 I:2004-20II.

32. Webb DJ, Weaver AM, Atkins-Brady TL, Gonias SL: Proteinases are isoform-specific regulators of the binding of transforming growth factor beta to alpha 2-macroglobulin. Biochem J 1996, 320(Pt 2):55 I-555.

33. Liu X, Wu H, Byrne M, Krane S, Jaenisch R: Type III collagen is crucial for collagen I fibrillogenesis and for normal cardiovascular development. Proc Natl Acad Sci U S A 1997, 94: I852- I856.

34. Sasaki T, Larsson H, Tisi D, Claesson-Welsh L, Hohenester E, Timpl $R$ : Endostatins derived from collagens $X V$ and $X V I I I$ differ in structural and binding properties, tissue distribution and anti-angiogenic activity. J Mol Biol 2000, 30 I: I I79-I I 90.

35. Hawley JA: Exercise as a therapeutic intervention for the prevention and treatment of insulin resistance. Diabetes Metab Res $\operatorname{Rev} 2004,20: 383-393$.

36. Dela F, Ploug T, Handberg A, Petersen LN, Larsen JJ, Mikines KJ, Galbo H: Physical training increases muscle GLUT4 protein and mRNA in patients with NIDDM. Diabetes 1994, 43:862-865.

37. van Weel V, Deckers MM, Grimbergen JM, van Leuven KJ, Lardenoye $J \mathrm{H}$, Schlingemann RO, van Nieuw Amerongen GP, van Bockel JH, van Hinsbergh VW, Quax PH: Vascular endothelial growth factor overexpression in ischemic skeletal muscle enhances myoglobin expression in vivo. Circ Res 2004, 95:58-66.

38. Semenza GL: Regulation of mammalian $\mathbf{O 2}$ homeostasis by hypoxia-inducible factor I. Annu Rev Cell Dev Biol 1999, 15:551-578.

39. Oh H, Takagi H, Otani A, Koyama S, Kemmochi S, Uemura A, Honda $Y$ : Selective induction of neuropilin-I by vascular endothelial growth factor (VEGF): a mechanism contributing to VEGFinduced angiogenesis. Proc Natl Acad Sci U S A 2002, 99:383-388.

40. Soker S, Miao HQ, Nomi M, Takashima S, Klagsbrun M: VEGFI65 mediates formation of complexes containing VEGFR-2 and neuropilin-I that enhance VEGF I65-receptor binding. J Cell Biochem 2002, 85:357-368.

4I. Claesson-Welsh L: Signal transduction by vascular endothelia growth factor receptors. Biochem Soc Trans 2003, 31:20-24.

42. Holash J, Maisonpierre PC, Compton D, Boland P, Alexander CR, Zagzag D, Yancopoulos GD, Wiegand SJ: Vessel cooption, regression, and growth in tumors mediated by angiopoietins and VEGF. Science 1999, 284:1994-1998.

43. Lobov IB, Brooks PC, Lang RA: Angiopoietin-2 displays VEGFdependent modulation of capillary structure and endothelial cell survival in vivo. Proc Natl Acad Sci U S A 2002, 99: I I 205-I I 2 I0.

44. Teichert-Kuliszewska K, Maisonpierre PC, Jones N, Campbell Al, Master Z, Bendeck MP, Alitalo K, Dumont DJ, Yancopoulos GD, Stewart DJ: Biological action of angiopoietin-2 in a fibrin matrix model of angiogenesis is associated with activation of Tie2. Cardiovasc Res 2001, 49:659-670.

45. Maisonpierre PC, Suri C, Jones PF, Bartunkova S, Wiegand SJ, Radziejewski C, Compton D, McClain J, Aldrich TH, Papadopoulos N, et al:: Angiopoietin-2, a natural antagonist for Tie2 that disrupts in vivo angiogenesis. Science 1997, 277:55-60.

46. Nishishita T, Lin PC: Angiopoietin I, PDGF-B, and TGF-beta gene regulation in endothelial cell and smooth muscle cell interaction. J Cell Biochem 2004, 91 :584-593.

47. Mathew S, Arandjelovic S, Beyer WF, Gonias SL, Pizzo SV: Characterization of the interaction between alpha2-macroglobulin and fibroblast growth factor-2: the role of hydrophobic interactions. Biochem / 2003, 374:123-129.

48. Soker S, Svahn CM, Neufeld G: Vascular endothelial growth fac tor is inactivated by binding to alpha 2-macroglobulin and the binding is inhibited by heparin. J Biol Chem 1993, 268:7685-769l.

49. Stenina OI, Byzova TV, Adams JC, McCarthy JJ, Topol EJ, Plow EF: Coronary artery disease and the thrombospondin single nucleotide polymorphisms. Int J Biochem Cell Biol 2004, 36:1013-1030.

50. Timmons JA, Gustafsson T, Sundberg CJ, Jansson E, Hultman E, Kaijser L, Chwalbinska-Moneta J, Constantin-Teodosiu D, Macdonald IA, Greenhaff PL: Substrate availability limits human skeletal muscle oxidative ATP regeneration at the onset of ischemic exercise. J Clin Invest 1998, I0 I:79-85.

5I. Winer J, Jung CK, Shackel I, Williams PM: Development and validation of real-time quantitative reverse transcriptasepolymerase chain reaction for monitoring gene expression in cardiac myocytes in vitro. Anal Biochem 1999, 270:41-49.
Publish with Biomed Central and every scientist can read your work free of charge

"BioMed Central will be the most significant development for disseminating the results of biomedical research in our lifetime. "

Sir Paul Nurse, Cancer Research UK

Your research papers will be:

- available free of charge to the entire biomedical community

- peer reviewed and published immediately upon acceptance

- cited in PubMed and archived on PubMed Central

- yours - you keep the copyright 